\title{
CUIDADORES E ESTRATÉGIAS NO CUIDADO AO DOENTE NA INTERNAÇÃO DOMICILIAR ${ }^{1}$
}

\author{
Cecília Maria Brondani², Margrid Beuter ${ }^{3}$, Neide Aparecida Titonelli Alvim ${ }^{4}$, Charline Szareski ${ }^{5}$, Lucimara \\ Sonaglio Rocha ${ }^{6}$
}

\footnotetext{
${ }^{1}$ Estudo elaborado com base na dissertação - Desafio de cuidadores familiares no contexto da internação domiciliar, Programa de Pós-Graduação em Enfermagem (PPGEnf) da Universidade Federal de Santa Maria (UFSM), 2008.

${ }^{2}$ Mestre em Enfermagem. Enfermeira do Hospital Universitário de Santa Maria. Rio Grande do Sul, Brasil. Email: ceciliabrondani@ hotmail.com

${ }^{3}$ Doutora em Enfermagem. Professora Adjunto do Departamento de Enfermagem PPGEnf/UFSM. Rio Grande do Sul, Brasil Email: margridbeuter@gmail.com

${ }^{4}$ Doutora em Enfermagem. Professora Associado do Departamento de Enfermagem Fundamental da Escola de Enfermagem Anna Nery da Universidade Federal do Rio de Janeiro. Rio de Janeiro, Brasil. Email: titonelli@globo.com

${ }^{5}$ Mestre em Enfermagem. Enfermeira da Prefeitura Municipal de Caxias do Sul. Rio Grande do Sul, Brasil Email: charlineszareski@ yahoo.com.br

${ }^{6}$ Mestranda em Enfermagem do PPGEnf/UFSM. Enfermeira do Hospital Beneficente Dr. César Santos de Passo Fundo. Rio Grande do Sul, Brasil Email: lucimarazz@hotmail.com
}

\begin{abstract}
RESUMO: O estudo teve como objetivo identificar as estratégias utilizadas pelos cuidadores familiares no cuidado ao doente crônico no contexto da internação domiciliar. Trata-se de uma pesquisa qualitativa, desenvolvida no Serviço de Internação Domiciliar de um hospital público no Rio Grande do Sul, da qual participaram 15 cuidadoras familiares. Para a produção dos dados utilizou-se o Método Criativo-Sensível e as dinâmicas Corpo-Saber e Almanaque. Foram desvelados os temas: expressões lúdicas no cuidado; o amor, o carinho e a paciência como expressões do cuidado; a espiritualidade como elemento do cuidado; a preocupação com o ambiente; e a importância da rede de apoio social. Os resultados demonstram que as cuidadoras realizam um cuidado singular direcionado para as necessidades específicas do doente, relacionando a história de vida, o contexto social e cultural em que ele está inserido. Portanto, o domicílio mostra-se como um espaço privilegiado para o cuidado humanizado.
\end{abstract}

DESCRITORES: Enfermagem. Assistência domiciliar. Doença crônica.

\section{CAREGIVERS AND STRATEGIES FOR HOME CARE PATIENTS}

\begin{abstract}
The study aimed to identify strategies used by family caregivers for chronic patients in home care. It is a qualitative study involving 15 caregivers developed in the Home Care Service of a public hospital in Rio Grande do Sul, Brazil. In order to produce data, a Creative-Sensitive Method, Body-Knowledge dynamics, and Almanac have been applied. The following topics were conveyed: playful expression in giving care; love, tenderness, and patience as expressions of care; spirituality as an element of care; concern with the environment; and the importance of social support networks. The results show that caregivers perform unique care directed to specific patient needs; relating to the story of life and to the social and cultural context in which it is inserted. Therefore, home is regarded as a privileged space for humanized care.
\end{abstract}

DESCRIPTORS: Nursing. Home nursing. Chronic disease.

\section{CUIDADORES FAMILIARES Y ESTRATEGIAS PARA EL CUIDADO DEL ENFERMO EN LA INTERNACIÓN DOMICILIARIA}

RESUMEN: El objetivo del presente estudio es identificar las estrategias utilizadas por los cuidadores familiares para la atención del enfermo crónico en el ámbito de la internación domiciliaria. Se trata de una investigación cualitativa, desarrollada en el Servicio de Internación Domiciliaria de un hospital público en Rio Grande do Sul, Brazil, de la cual participaron 15 cuidadores familiares. La recolección de los datos se hizo por el Método Creativo-Sensible y las dinámicas Cuerpo-Saber y Almanaque. Se definieron los siguientes temas: expresiones lúdicas en el cuidado; el amor, el cariño y la paciencia como expresiones del cuidado; la espiritualidad como elemento del cuidado; la preocupación con el entorno; y la importancia de la red de apoyo social. Los resultados demuestran que las cuidadoras realizan un cuidado singular dirigido a las necesidades específicas del enfermo, relacionando la historia de vida, el entorno social y cultural en que está inserto. Por lo tanto, el domicilio se muestra como un espacio privilegiado para el cuidado humanizado.

DESCRIPTORES: Enfermería. Atención domiciliaria de salud. Enfermedad crónica. 


\section{INTRODUÇÃO}

O cuidado a doentes crônicos no domicílio vem crescendo gradativamente no Brasil. Por meio da assistência domiciliar vem sendo construída uma nova lógica de atuação dos profissionais de saúde, que se deslocam até o domicílio para atender esta demanda.

Nesse contexto, a assistência domiciliar apresenta-se como uma importante modalidade de atendimento à saúde. A assistência domiciliar é um termo genérico que representa várias modalidades de atenção à saúde desenvolvida no domicílio, entre elas, a visita domiciliar, o atendimento e a internação domiciliar. ${ }^{1} \mathrm{O}$ funcionamento de serviços que prestam assistência domiciliar é regulamentada pela Agência Nacional de Vigilância Sanitária.

A internação domiciliar caracteriza-se por um conjunto de atividades prestadas no domicílio à pessoas clinicamente estáveis que necessitam de cuidados que possam ser realizados em casa, desde que assistidas por equipe exclusiva para este fim. ${ }^{2}$ O desenvolvimento dessa modalidade de assistência ressalta a relevância do contexto da família e do cuidador familiar para o atendimento ao doente. Existe a necessidade da família ser coparticipante do processo de cuidar, pois os profissionais da área pouco podem fazer pela saúde do doente, quando a família não assume o cuidado. ${ }^{3}$

A pessoa que tem a função de cuidar de alguém com algum grau de dependência física ou mental e que necessite de ajuda (total ou parcial) para a realização de atividades da vida cotidiana é considerado cuidador. ${ }^{4-6} \mathrm{O}$ cuidador familiar é aquele que assume uma atividade não remunerada, responsabilizando-se pela mesma, de forma espontânea, instintiva, por disponibilidade, ou ainda, por obrigação, solidariedade, ou como um sentimento natural de gratidão, para retribuir cuidados recebidos na infância. ${ }^{7} \mathrm{O}$ cuidador no contexto da internação domiciliar desempenha um papel importante no cuidado ao indivíduo enfermo, constituindo-se no elo interativo entre doente e equipe de saúde. ${ }^{8}$ Portanto, destaca-se a importância de ressignificar as atividades de cuidado desenvolvidas pela família, capacitando o cuidador para a realização desta atividade que, na maioria das vezes, é executada de forma solitária e ininterrupta.

Pela importância do papel do cuidador familiar no processo da internação domiciliar, verifica-se a necessidade de identificar as estratégias utilizadas por ele, de forma que este conhecimento possibilite aos profissionais da saúde contribuir no cuidado, valorizando os sujeitos envolvidos. Assim, este estudo teve como objetivo: identificar as estratégias utilizadas pelos cuidadores familiares no cuidado ao doente crônico no contexto da internação domiciliar.

\section{METODOLOGIA}

Trata-se de um estudo exploratório, de abordagem qualitativa, desenvolvido com cuidadores familiares de doentes crônicos assistidos pelo Serviço de Internação Domiciliar de um hospital público, no interior do Rio Grande do Sul. O serviço atende indivíduos portadores de doenças crônicas com estabilidade clínica, em condições de prosseguir com o tratamento no domicílio. A produção dos dados ocorreu no mês de maio de 2008.

A inclusão dos participantes obedeceu aos critérios de ser cuidador com grau de parentesco e cuidar do doente no serviço de internação domiciliar sem remuneração financeira. Os participantes do estudo foram 15 cuidadores, sendo 14 do sexo feminino e um do sexo masculino. Frente à predominância de mulheres neste estudo, adotou-se o termo cuidadoras. A idade das participantes variou entre 25 a 75 anos. Em relação à sua ocupação, sete realizavam atividades do lar. O período de tempo que as cuidadoras assistiam seus familiares variou em torno de dois meses a 12 anos.

O Método Criativo-Sensível (MCS) foi utilizado para a produção dos dados. ${ }^{9}$ Este método fundamenta-se no desenvolvimento de Dinâmicas de Criatividade e Sensibilidade (DCS). Nas DCS são utilizadas técnicas como a entrevista coletiva, a discussão grupal e a observação participante, conjugadas à produção artística dos participantes, desenvolvidas com base na temática central apresentada ao grupo. O propósito do método é alcançar o potencial sensível dos participantes por meio de práticas artísticas, facilitando a expressão de sua subjetividade, além de proporcionar a interação entre o grupo e a pesquisadora.

Foram realizadas duas dinâmicas cuja temática central foi "o cuidado desenvolvido pelo cuidador no domicílio e as suas necessidades para realizar este cuidado". Na primeira dinâmica, "Corpo-Saber", as participantes discutiram como cuidavam do corpo do seu familiar no domicílio. Na segunda dinâmica, "Almanaque", as participantes debateram as necessidades e as estratégias utilizadas por elas no cuidado do familiar no domicílio. Os dados gerados no âmbito das dinâmicas foram registrados em um diário de campo 
e um gravador de áudio. Após, foram transcritos e compilados, constituindo-se nos relatórios das atividades, fontes primárias da pesquisa.

A análise dos dados foi desenvolvida a partir dos pressupostos conceituais da análise de discurso francesa. ${ }^{10}$ Etimologicamente, a palavra discurso "tem em si a idéia de curso, de percurso, de correr por, de movimento. O discurso é assim palavra em movimento, prática de linguagem: com o estudo do discurso observa-se o homem falando". 10:15 Logo, as palavras ditas no nosso cotidiano chegam até nós carregadas de sentidos e significados diversos, que se movimentam e se resignificam continuamente. Por essa razão, as palavras são "sempre as mesmas, mas ao mesmo tempo, sempre outras". 10:36 Deste modo, a análise de discurso visa "interrogar os sentidos estabelecidos em diversas formas de produção (verbal ou não verbal), bastando que sua materialidade produza sentidos para interpretação". 11:680

O relatório das dinâmicas compôs o corpus de análise que foi submetido a uma primeira análise que objetivou dar materialidade linguística ao texto. Após, a análise foi aprofundada procurando dar sentido ou significado às palavras por meio dos seguintes dispositivos analíticos: a paráfrase, a polissemia e a metáfora.

As dinâmicas foram organizadas no formato de quadros analíticos que apresentaram as situações existenciais cujos discursos das cuidadoras familiares permeavam o cuidado realizado no domicílio. Essas situações existenciais emergiram nas discussões grupais no âmbito de cada dinâmica, representando o movimento discursivo das enunciações das cuidadoras familiares.

A pesquisa foi aprovada pelo Comitê de Ética em Pesquisa da Universidade Federal de Santa Maria, sob o protocolo n ${ }^{\circ} 23081.000145 / 2008-19$, CAE 0004.0.243.000-08. Foram observados os princípios éticos da Resolução 196/96 do Conselho Nacional de Saúde/MS. ${ }^{12}$ As participantes assinaram o Termo de Consentimento Livre e Esclarecido, após serem elucidadas sobre o objetivo do estudo. O sigilo foi garantido com a utilização dos seguintes pseudônimos: Lis, Orquídea, Preta, Primavera, Rosa e Margarida.

\section{RESULTADOS E DISCUSSÃO}

As cuidadoras familiares, representadas pelos seus pseudônimos, trouxeram para discussão suas experiências de cuidado, apontando estratégias utilizadas por elas no cuidado ao doente crônico, no contexto da internação domiciliar. Ao longo do debate, no movimento dialógico no interior das dinâmicas, emergiram os temas: "expressões lúdicas no cuidado"; "o amor, o carinho e a paciência como expressões do cuidado"; "a espiritualidade como elemento do cuidado"; "a preocupação com o ambiente"; e "a importância da rede de apoio social".

\section{Expressões lúdicas no cuidado}

A oferta de um ambiente lúdico demonstra a sensibilidade e a criatividade no cuidado. Isto pode ser manifestado através de ações, como ligar rádio, ver televisão, oferecer-lhes livros, revistas. Olúdico se manifesta, não só pela atividade em si, mas pela maneira, pela postura de quem realiza a ação. ${ }^{13}$

A enunciação dialógica de Lis aponta para a preocupação, não apenas com as atividades instrumentais, necessárias para a realização da atividade de cuidar no domicílio, mas para a necessidade de considerar as diferenças, as peculiaridades de cada indivíduo.

Ele [irmão doente] está regredindo cada vez mais. A gente sabe! Ele não consegue enxergar mais por causa da doença. Mas a gente deixa a TV ligada nos programas que ele gosta. Ele escuta o dia inteiro, só as músicas que ele gosta, as gaúchas e sertanejas (Lis).

$\mathrm{Na}$ enunciação de seu discurso, a cuidadora deixa transparecer sensibilidade e carinho ao revelar que mantém o aparelho de televisão ligado nos programas e músicas que seu irmão gosta, apesar dele não enxergar. Ela sabe que fazer as coisas que o doente aprecia ajuda a amenizar o seu sofrimento, proporcionando bem-estar e conforto.

Na relação de cuidado é importante considerar a totalidade do ser humano, isto é, sua constituição, física, emocional, social, cultural, ética, espiritual/religiosa; só assim é possível proporcionar um cuidado individualizado, promover o bem-estar físico e psicológico do ser ao qual estamos cuidando. O ser humano é constituído de uma estrutura complexa e pluridimensional, que se expressa de diferentes maneiras, porém é indivisível e deve ser considerado em sua totalidade. ${ }^{14}$ Partindo-se da premissa de que a pessoa humana é única, então, $\mathrm{o}$ ato de cuidar dessa pessoa também deve ser singular. Cada pessoa tem sua própria realidade e especificidade que devem ser respeitadas.

As situações existenciais concretas dos cuidadores desveladas, em suas produções artísticas, permitem avançar na análise e revelam a conversa como um novo elemento que faz parte do cotidia- 
no do cuidar, o qual valoriza a subjetividade dos envolvidos no processo da assistência domiciliar. A conversa é considerada um elemento importante na relação entre o cuidador e o seu familiar doente no momento da realização do cuidado, tanto no ambiente hospitalar quanto no domicílio. As cuidadoras apontam a conversa como um instrumento de cuidado utilizado no domicílio:

[...] é conversar! Apesar do " $L$ " não conseguir falar, a gente fala, conversa com ele. [...] Cantar! Nós cantamos as musiquinhas que ele gosta (Orquídea).

[...] conversar, fazer companhia, brincar com o paciente. Isso é importante! Ele não está falando, mas a gente conversa com ele [...]. Ter calma, para aprender! Apesar deles não falarem é preciso aprender, decifrar o que eles sentem (Preta).

Os discursos das cuidadoras familiares revelam a importância da conversa durante a realização do cuidado, demonstrando a necessidade da afetividade e das tecnologias leves no espaço de cuidado domiciliar, visto que a preocupação da cuidadora vai além da realização dos cuidados corporais. Percebe-se o pensar das cuidadoras em relação à necessidade de interação com o seu familiar e de estar atento às expressões não-verbais manifestadas pelo doente.

Os discursos de Orquídea e Preta trazem a concepção do lúdico no cuidado, representado pela conversa, brincadeira, canto e escuta. O lúdico emerge no cuidado quando cuidamos com criatividade e sensibilidade, transmitindo afeto, solidariedade, demonstrando interesse, empatia, compaixão e zelo pelo outro. A conversa, quando imbuída destas características lúdicas, atribui maior qualidade ao cuidado de enfermagem. ${ }^{13}$

As expressões lúdicas foram utilizadas por cuidadores familiares de pessoas com Acidente Vascular Cerebral (AVC), ao oferecerem ao doente atividades diferenciadas, tais como: passeio, alimento diferente e música. Esses cuidados promoveram o bem-estar físico, mental e social do doente, proporcionando momentos de alegria e descontração, auxiliando na reabilitação e no fortalecimento do seu sistema imunológico..$^{15}$

\section{O amor, o carinho e a paciência como expres- sões do cuidado}

As cuidadoras familiares, fundamentadas na sua experiência de cuidar em casa, revelaram a importância de ir além do cuidado físico.

O carinho e o amor são muito importantes (Preta).
O amoré a base para cuidar de uma pessoa. Depois vem a higiene, um ambiente de qualidade saudável. $O$ respeito também, a responsabilidade que eu tenho em relação àquela pessoa é cada vez maior. O bem-estar, o carinho [...]. É uma das coisas principais (Primavera).

Suas falas salientam que o amor é imprescindível quando se cuida de alguém. O sentimento vem em primeiro lugar, permeando as demais atividades de cuidado realizadas no domicílio. Acrescentam ainda que o respeito, a responsabilidade e o carinho com o familiar doente são elementos importantes no cuidado. O cuidado na dimensão afetiva pode ser manifestado por um gesto, um toque, um sorriso, ou por um olhar atento no momento da sua realização. Isso demonstra preocupação com o outro e confere qualidade à ação de cuidar.

Portanto, é preciso considerar que a diferença entre os seres humanos e as máquinas está no sentimento, na capacidade de envolver-se, de perceber e ser afetado pelo que está ao seu redor. É pelo sentimento que as pessoas, coisas e situações se tornam importantes para nós, e, por isso, cuidamos. Assim, o amor é considerado um fenômeno biológico, que dá origem à sociedade e conceitua-se como "[...] um fenômeno cósmico e biológico. Ao chegar ao nível humano, ele se revela como a grande força de agregação, de simpatia e de solidariedade" ${ }^{\prime 6: 114}$

No cuidado ao doente crônico, a paciência deve ser considerada para auxiliar de modo mais eficiente na sua recuperação. As cuidadoras relatam a importância da paciência na realização dos cuidados no domicílio:

[...] os cuidados que tu precisa ter? Claro que é paciência! Como todos falaram (Rosa).

[...] a paciência a gente tem que ter sempre. Nunca pode deixar de ter [...]. A paciência (Primavera).

O dito e o não dito nas enunciações dialógicas das cuidadoras familiares evidenciam os elementos, considerados necessários, em suas práticas de cuidado no domicílio: carinho, amor e paciência. $\mathrm{O}$ carinho, o amor e a paciência prestado pelas cuidadoras domiciliares são ingredientes necessários para a realização do cuidado domiciliar. ${ }^{17}$

\section{A espiritualidade como elemento do cuidado}

A espiritualidade é difícil de ser definida. Ela representa a busca individual do ser humano para compreender o sentido da vida e da existência. ${ }^{18}$ Nesse sentido, pode ser entendida de diversas formas, de acordo com a percepção de cada pessoa. Pode ser vista como energia, transcendência, 
plano superior, luz, e expressada de acordo com a religião adotada, por meio de orações, meditação e rituais que proporcionam o alívio para o sofrimento. ${ }^{19}$ No âmbito das dinâmicas, as cuidadoras revelam outras dimensões do cuidado:

[...] eu sou muito religiosa e eu sempre penso que sem ter fé tu não vai conseguir. Principalmente Deus [enfatiza a palavra], que nos dá força (Margarida).

[...] a féé a força que tem que ter pra poder superar e conviver com o que é preciso. Essas coisas que eu acho importante (Primavera).

As enunciações das cuidadoras exteriorizam a necessidade de buscar apoio e força na fé para superar as dificuldades do dia a dia. A crença em uma força superior possibilita, às cuidadoras familiares, cultivar a esperança, acreditar que tudo vai dar certo e que as atividades de cuidado prestadas ao familiar doente contribuem para a sua recuperação. Nesse sentido, o cuidador familiar mencionou "[...] a fé, como um atributo necessário para lhe proporcionar apoio e alívio de tensões". ${ }^{19: 142}$ Logo, a fé e a esperança ajudam tanto o doente quanto o cuidador na assistência domiciliar.

A fé e a religião/religiosidade são fatores mediadores que auxiliam os familiares no enfrentamento do cuidado domiciliar. A religião é considerada, por diversos autores, um importante aliado no processo de aceitação da doença e das atividades impostas por ela., ${ }^{72-22}$ É relevante salientar que a espiritualidade está na essência do ser humano e se manifesta na relação com o outro. A espiritualidade pode ser expressa no cuidado quando contempla a atenção, o carinho e o amor da cuidadora pelo doente, manifestando-se na capacidade de ouvir, dialogar e compreender o outro. ${ }^{18}$

\section{A preocupação com o ambiente}

O ambiente de cuidado, como dimensão contextual, tem diversos significados para os cuidadores. Para alguns, o ambiente representa apenas o espaço físico, uma boa iluminação, ventilação, instalações adequadas e seguras. Para outros cuidadores, tem um significado maior, transcende ao elemento físico, representa um espaço de conforto, harmonia e bem-estar que contribuiem positivamente para a recuperação do doente. ${ }^{23}$

A importância deste aspecto surge no discurso das cuidadoras, trazendo elementos importantes para a discussão grupal.

[...] tem que ter tudo, o silêncio, tem que ter a higiene [...], condições [...]. Tudo para ajudar [...] (Primavera).
O ambiente, a higiene. Um ambiente bom. Prazer, lazer e saúde. Conforto para todos em casa, carinho, carinho bastante (Orquídea).

Em relação à promoção da higiene, de um ambiente agradável e afetivo no cuidado, a Teoria do Cuidado Transpessoal de Jean Watson, em seu oitavo elemento de cuidado, destaca a necessidade de criar-se um ambiente de cura, em que são potencializados o conforto, a paz e a dignidade do doente. ${ }^{24}$

A presença de uma pessoa doente na família desencadeia várias mudanças, sendo uma delas, a necessidade de adaptar o ambiente físico para suprir as necessidades do familiar doente. Outra necessidade diz respeito às mudanças que ocorrem na vida pessoal do cuidador, tais como: a inversão de papéis na relação familiar, o adiamento de projetos de vida, entre outros. A falta de uma estrutura física adequada dificulta a realização de algumas atividades e acarreta o desgaste físico das cuidadoras manifestado por dores no corpo resultantes do esforço para a realização das atividades diárias, tais como higiene corporal, troca de fraldas e mudança de decúbito. ${ }^{21}$ No entanto, os cuidadores são capazes de definir prioridades, realizar adaptações estruturais para superar as limitações do espaço físico. Utilizando a criatividade e o bom senso, os cuidadores realizam adaptações na casa com o objetivo de manter o doente no domicílio e proporcionar um ambiente favorável para o cuidado. ${ }^{17}$

Após a adaptação do ambiente físico, do estabelecimento da rotina de cuidados, as cuidadoras percebem que também o aspecto social de sua vida foi alterado. Surge então, a necessidade de uma estrutura familiar/formal que facilite e ampare a tarefa de cuidar no domicílio.

\section{A importância da rede de apoio social}

Cuidar de uma pessoa doente é uma tarefa árdua e difícil, por isso, a ajuda e a colaboração de outras pessoas são importantes na efetivação do cuidado. ${ }^{14}$ Nessa perspectiva, "o apoio social ao idoso e seu cuidador tem como objetivo principal diminuir os aspectos negativos provocados pela tarefa de cuidar, contribuir para a melhoria da saúde do cuidador e refletir positivamente na qualidade de cuidados prestados". ${ }^{25: 49}$ Os autores do estudo classificam o apoio social em duas categorias: o informal e o formal. O apoio informal é representado pelas relações sociais que são estabelecidas entre os familiares, amigos, vizinhos, parentes próximos 
e grupos comunitários; o formal é representado especialmente pelos serviços de saúde.

A presença de uma rede de suporte social, representada por outros membros da família, amigos e profissionais da saúde constitui-se em uma importante estratégia de diminuição da sobrecarga. ${ }^{22} \mathrm{~A}$ enunciação dialógica da cuidadora define sua visão a respeito do apoio e da ajuda no cuidado:

[...] parceria! Porque a gente não faz nada sozinho. A parceria dos familiares e a ajuda em geral [...], até de vizinhos (Margarida).

No movimento do diálogo, a cuidadora relata a dificuldade em conseguir ajuda para o cuidado domiciliar:

[...] envolve toda a família [...], mas a gente não consegue envolver toda a familia, né! Cada um tem suas coisas. Lá em casa mesmo, são duas que cuidam mais a mãe (Primavera).

O cuidado deve envolver toda a família. Porém, muitas vezes, isso não é possível e apenas uma ou duas pessoas assumem a tarefa de cuidar do familiar doente. Nesse sentido, a importância de poder contar com a ajuda de outras pessoas facilita o cuidado, e permite ao cuidador sair daquele ambiente por algum tempo, espairecer, diminuindo a sobrecarga. ${ }^{24}$

Assim, foi observado que o apoio formal, representado pelos serviços de saúde, é insuficiente e não oferece suporte e proteção efetiva ao cuidador que, muitas vezes, se vale da ajuda solidária de voluntários para manter o cuidado domiciliar de forma digna.

Todos estes aspectos revelam que o cuidado no domicílio não é uma tarefa fácil. As cuidadoras familiares, ao assumirem a responsabilidade de cuidar no domicílio, precisam desempenhar, simultaneamente, uma diversidade de tarefas. A construção de uma rede de solidariedade entre os diferentes membros da família, amigos, vizinhos e serviços de saúde é uma estratégia salutar e desejada para auxiliar no desenvolvimento dessa atividade.

\section{CONCLUSÕES}

Os resultados demonstraram que as cuidadoras realizam um cuidado singular, direcionado para as necessidades específicas do doente, por conhecer e conviver com ele diariamente. Conhecer a história de vida, o contexto social e cultural em que o indivíduo está inserido, possibilita a individualização do cuidado.
Proporcionar momentos de lazer e descontração para o doente é parte desta individualização. A conversa, a escuta, a necessidade de estar atento às expressões verbais e não verbais do doente, a oferta de opções de lazer, amenizam o sofrimento e proporcionam bem-estar e conforto ao doente. A utilização de expressões lúdicas no cuidado foi uma das estratégias adotadas pelas cuidadoras.

Outra estratégia utilizada pelas cuidadoras foi agregar a esperança, a fé no agir cotidiano, acreditando nos benefícios da atividade que desenvolviam durante a internação domiciliar. A fé e a religião surgem como apoio na superação das dificuldades e no alívio das tensões diárias.

A colaboração de outras pessoas, membros da família, amigos e/ou profissionais de saúde tornam o cuidado domiciliar uma atividade mais leve, melhorando a qualidade de vida da cuidadora, diminuindo a sua sobrecarga física, emocional, econômica e social. Dessa forma, a construção de uma rede de solidariedade entre os diferentes membros da família, amigos, vizinhos, serviços de saúde, é uma estratégia salutar para auxiliar no desenvolvimento da atividade de cuidar no domicílio.

O domicílio torna-se um espaço privilegiado para o cuidado, caracterizado pela preocupação com a integralidade, com a singularidade do ser humano e de valorização da intersubjetividade, da relação e do respeito ao outro. $\mathrm{O}$ ato de cuidar no domicílio é percebido, por quem cuida, como uma oportunidade de crescimento e realização pessoal na medida em que permite o desenvolvimento de novas habilidades e a expressão de sentimentos de solidariedade, amor, respeito, empatia, dignidade e inserção social.

Entende-se que as estratégias relatadas pelas cuidadoras podem contribuir com subsídios que possibilitam repensar a prática da enfermagem no âmbito domiciliar. Nesse sentido, ao reconhecer e utilizar a sua sensibilidade em ações que transcendam o procedimento técnico do cuidado, a enfermagem poderá promover o conforto, o bem-estar e a dignidade do doente nos diversos cenários do cuidar.

\section{REFERENCIAS}

1. Brasil. Resolução $n^{\circ} 81$, de 10 de outubro de 2003 : dispõe das normas de funcionamento de serviços que prestam Assistência Domiciliar. Agência Nacional de Vigilância Sanitária, Brasília, DF, 10 Out 2003[acesso 2006 Set 20]. Disponível em: 
http://www4.anvisa.gov.br/base/visadoc/CP/ CP\%5B5668-8-0\%5D.PDF

2. Brasil. Portaria $n^{\circ} 2.529$ de 19 de outubro de 2006. Institui a internação domiciliar no âmbito do SUS. Ministério da Saúde, Brasília, DF, 19 Out 2006 [acesso 2007 Jun 12]. Disponível em: http:/ / www. ciape.org.br/AtenDom2529.pdf

3. Marcon SS, Waidman MAP, Careira L, Decesáro MN. Compartilhando a situação de doença: o cotidiano de famílias de pacientes crônicos. In: Elsen I, Marcon SS, Silva MRS, organizadores. O viver em família e sua interface com a saúde e a doença. Maringá (PR): Eduem; 2002. p. 311-34.

4. Marcon SS, Lopes MC, Atunes CRM, Fernandes J, Waidman MAP. Family caregivers of chronically ill people: a bibliographic study. Online Braz J Nurs. 2006 [acesso 2007 Nov 12]; 5(1). Disponível em: http://www.objnursing.uff.br/index.php/ nursing/article/view/145

5. Souza WGA, Pacheco WNS, Martins JJ, Barra DCC, Nascimento ERP. Educação em saúde para leigos no cuidado ao idoso no contexto domiciliar. Arq Catarin Med. 2006 Out-Dez; 35(4):56-63.

6. Duarte YAO. O cuidador no cenário assistencial. Mundo Saúde. 2006 Jan-Mar; 30(1):37-44.

7. Cattani RB, Girardon-Perlini NMO. Cuidar do idoso doente na voz de cuidadores familiares. Rev Eletr Enf [online]. 2004 [acesso 2006 Jun 20]; 6(2). Disponível em: http://www.revistas.ufg.br/index. php/fen/article/view/812/930

8. Brondani CM. Desafio de cuidadores familiares no contexto da internação domiciliar. [dissertação]. Santa Maria (RS): Universidade Federal de Santa Maria, Programa de Pós-Graduação em Enfermagem; 2008.

9. Cabral IE. O método criativo-sensível: alternativa de pesquisa na enfermagem. In: Gauthier JH, Cabral IE, Santos I, Tavares CMM, organizadores. Pesquisa em enfermagem: novas metodologias aplicadas. Rio de Janeiro (RJ): Guanabara Koogan; 1998. p. 177-203.

10. Orlandi EP. Análise de discurso: princípios e procedimentos. $4^{\mathrm{a}}$ ed. Campinas (SP): Pontes; 2002.

11. Caregnato RCA, Mutti R. Pesquisa qualitativa: análise de discurso versus análise de conteúdo. Texto Contexto Enferm. 2006 Out-Dez; 15(4):679-84.

12. Ministério da Saúde (BR), Conselho Nacional de Saúde, Comitê Nacional de Ėtica em Pesquisa em Seres Humanos. Resolução 196, de 10 de outubro de 1996: diretrizes e normas regulamentadoras de pesquisa envolvendo seres humanos. Brasília (DF); 1996.
13. Beuter M. Expressões lúdicas no cuidado: elementos para pensar/fazer a arte da enfermagem. [tese]. 2004. Rio de Janeiro (RJ): Universidade Federal do Rio de Janeiro, Escola de Enfermagem Anna Nery; 2004.

14. Torralba FR. Antropologia do cuidar. Petrópolis (RJ): Vozes; 2009.

15. Bochi SCM, Ângelo M. Interação cuidador familiarpessoa com AVC: autonomia compartilhada. Ciênc Saúde Coletiva. 2005 Jul-Set; 10(3):729-38.

16. Boff L. Saber cuidar: ética do humano - compaixão pela terra. Petrópolis (RJ): Vozes, 1999.

17. Sena RR, Silva KL, Rates HF, Vivas KL, Queiroz CM, Barreto FO. O cotidiano da cuidadora no domicílio: desafios de um fazer solitário. Cogitare Enferm. 2006 Mai-Ago; 11(2):124-32.

18. Dezorzi LW. Diálogos sobre a espiritualidade no processo de cuidar de si e do outro para a enfermagem em terapia intensiva. [dissertação]. Porto Alegre (RS): Universidade Federal do Rio Grande do Sul, Programa de Pós-Graduação em Enfermagem; 2006.

19. Luzardo AR, Waldman BF. Atenção ao familiar cuidador do idoso com doença de Alzheimer. Acta Sci Health Sci. 2004 Jan-Jun; 26(1):135-45.

20. Pedro KS, Marcon SS.Profile and life experience of informal caretakers of patients with chronic disease. An exploratory study. Online Braz J Nurs. 2007 [acesso 2007 Nov 21]; 6. Available from: http:// www.uff.br/objnursing/index.php/nursing/ article/view/653/153

21. Silveira TM, Caldas CP, Carneiro TF. Cuidando de idosos altamente dependentes na comunidade: um estudo sobre cuidadores familiares principais. Cad Saúde Pública. 2006 Jan-Ago; 22(8):1629-38.

22. Bandeira M, Barroso SM. Sobrecarga das familias de pacientes psiquiátricos. J Bras Psiquiatr. 2005 Jan-Mar; 54(1):34-46.

23. Silva AL. O cuidado no encontro de quem cuida e de quem é cuidado. In: Meyer DE, Waldow VR, Lopes MJM, Organizadores. Marcas da diversidade: saberes e fazeres da enfermagem contemporânea. Porto Alegre (RS): Artmed, 1998. p.195-241.

24. Watson J. Watson's theory of human caring and subjective living expeiences: carative factors. Texto Contexto Enferm. 2007 Jan-Mar; 16(1):129-35.

25. Nardi EFR, Oliveira MLF. Conhecendo o apoio social ao cuidador familiar do idoso dependente. Rev Gaúcha Enferm. 2008 Mar; 29(1):47-53. 